\title{
SAMPLING AND SUB-SAMPLING OF GRANULAR WASTE: SIZE OF A REPRESENTATIVE SAMPLE IN TERMS OF NUMBER OF PARTICLES
}

\author{
Pierre Hennebert ${ }^{1}$ and Giovanni Beggio 2,* \\ ${ }^{1}$ Ineris (French National Institute for Industrial Environment and Risks), BP 2, F-60550 Verneuil-en-Halatte, France. \\ ${ }^{2}$ Department of Civil, Environmental and Architectural Engineering, University of Padova, Via Marzolo 9, 35131, Padova, Italy
}

Article Info:

Received:

29 January 2021

Revised:

24 September 2021

Accepted:

29 September 2021

Available online:

29 November 2021

Keywords:

EN 14899

EN 15002

CEN/TR 15310-1

Variability

Uncertainty

Waste characterization

\begin{abstract}
This paper elucidates the theoretical principles behind the calculation of the size of a representative sample of granular solid waste. The key concept is the number of particles that must be present in a sub-portion of matter to be representative of a larger portion of matter. This depends on the fraction of particles in the waste batch showing the properties of interest, which shall be measured. A representative sample must include a fraction of particles of interest reliably similar to that of the waste batch to be characterized, with a controlled variability. In this context, it is demonstrated that the number of particles of interest that must be collected in a representative sample is 100 . From this requirement, the mass of a representative sample can be calculated based on the knowledge of the frequency of particles of interest of the waste lot to be characterized. Data on particles concentrations in different samples of WEEE plastic scraps exemplifies how the presence in the sample of enough rare particles showing the property of interest is key to ensure reliable measurements. Further, the assumptions made on the controlled degree of variability to determine the minimum number of particles are discussed based on data on achievable intra- and inter-laboratory variability of analytical standards for waste characterization. Accordingly, the mass of laboratory samples and test portions recommended in published sampling plans or analytical standards are assessed for the occurring number of particles.
\end{abstract}

\section{INTRODUCTION}

Reliable data on characterization of granular solid wastes are needed to allow informed decisions on the appropriate way in which they should be treated (or not), recovered or disposed of. However, for practical and economical reason, it is impossible to analyse the entire batch of waste to be managed. Therefore, smaller portions, also known as samples, shall be collected, and brought to the laboratory to be further analysed. Similarly, the lab operators will investigate smaller fractions, usually defined as test portions, derived from the sub-sampling of the laboratory sample. Data reliability is thus ensured $i)$ when the specific analytical standard is correctly performed and ii) when laboratory samples and test portions can be thought as "representative", i.e., their composition is "reliably" similar to the one of the waste lot to be characterized.

From the prospective of analytical chemistry and chemical metrology, the degree of reliability linked to an analytical result is determined by the magnitude of its uncertainty, calculated based on the achieved variance from repeated analysis performed on a set of identical samples (EURACHEM and CITAC, 2012; 2019). Similarly, the so-called "Theory of Sampling" (ToS) refers to the variance originating from different specific types of "errors" (Gy, 2004a; 2004b; 2004c; 2004d). Despite being developed independently, both approaches agree on describing the total variance as constituted by the sum of several sources, the main being the analytical step and the sampling activity.

While much effort is usually provided to the correct performance of the analysis, the theory (and practice) of representative sampling is still not mastered in the waste community.

Indeed, the EU technical standards on waste sampling provide qualitative information on how to perform representative sampling and quantitative methods to determine the mass of a representative laboratory sample or test portion: these instructions are resumed, for each waste stream, within a so-called "sampling plan" (EN 14899, 2016; CEN/TR 15310-1, 2007; EN 15002, 2015). Nevertheless, the aforementioned standards do not explain the theoretical principles behind these formulations. Notably, only Khodier 
et al., (2019), remarkably addressed this topic, but focusing on a specific waste type sampled according to a national Austrian standard, which was judged not optimal for the type of analysis performed (i.e., material composition analysis).

In this context, this paper addresses the theoretical bases behind the proposed formulas for the determination of the size of a representative sample of granular solid waste in the related EU technical standards. In doing so, it introduces the key concept of the "number of particles" that should be present in a sample to be representative of a bigger batch of granular solid material, assuming a wanted/controlled variability between equivalent samples, and a skewed distribution, among particles, of the parameters to be quantified (this latter to be known a priori or estimated). In particular, the equations presented in sampling standards are revisited here starting from that distribution. Here, the word "particle" refers to the physically distinct portion of solid mater not bound to the other portions at the time of sampling. It is equivalent to part, piece or scrap.

Sampling plans address the waste heterogeneity/variability at the scale of a population (for instance annual production or daily stream of waste) by considering factors that influence ("stratify") the constituents in the population (EN 14899, 2016). More "homogeneous" populations or sub-populations are then sampled. Several mono- or composite- (i.e., made of increments) representative samples are taken and analysed. However, this paper addresses only the heterogeneity/variability occurring in laboratory samples taken from a population or sub-population of solid waste, as well as the test portion. In other words, only the variability of the properties of individual particles making up the sample are considered here and used to calculate the mass of representative samples. This is referenced as "fundamental variability" in the ToS. This implies that the contributes to variability derived from both the so-called "incorrect" sampling errors (i.e., originating from blunders in sampling performance) or the unavoidable "grouping and segregation error" (Gy, 2004a; 2004b; 2004c; 2004d), that covers the spatial heterogeneity (due to particle size distribution) of the waste, are not considered in this study. However, a method to calculate the size of a representative sample considering both the particles properties distribution and the possible size-property relationships will be proposed by the authors in a following paper.

Further, this paper presents data about the occurring distributions among particles of wastes of parameters of interest. The influence of these distributions on the results measured in the lab is also discussed.

The assumptions made to derive the number of particles in a representative sample are then evaluated based on the variability monitored in real cases. In particular, the analytical variability (intra- and inter-laboratory) from the analysis of i) reference materials, ii) laboratory samples and iii) standards validation trials were used.

Finally, the size of several samples and test portions, as indicated by published sampling plans and analytical standards usually applied for waste, are assessed in terms of number of particles to check if the requirement proposed in the theoretical part can be fulfilled.

\section{REPRESENTATIVE SAMPLING IN TERMS OF NUMBER OF PARTICLES}

\subsection{Theoretical basics: binomial probability distri- bution}

Sampling performance allows to produce, from a population of discrete material (e.g., a waste lot) a subset (i.e., a "sample"), the elements of which reliably resemble the population itself in terms of several characteristics of interest. Also, a sampling action can be conceptualized as a selection, from a batch, of a number $n$ of different elements ("particles"). In these terms, a sample can be thought as the sum of $n$ particles individually drawn from a lot. The sample will be considered representative if characterized by a reliably similar proportion, occurring between its elements, of the properties of the population (i.e., the batch of materials to be characterized).

Given this background, the probability to get a specific number $\mathrm{x}$ of particles showing a researched characteristic, within $n$ repeated drawings (of 1 particle) from a lot characterized by a fraction $\mathrm{p}$ of the researched feature (or, better, the fraction of particles in the lot showing the presence of the researched characteristic), can be mathematically interpreted by the binomial distribution $B(x ; n, p)$ :

$B(x ; n, p)=\frac{n !}{x !(n-x) !} p^{x}(1-p)^{n-x}$

The distribution $\mathrm{B}(\mathrm{x} ; \mathrm{n}, \mathrm{p})$ is characterized by an expected value $\mu$ (i.e. the value of $x$ characterized by highest probability) and by a variance $\sigma^{2}$ (i.e. how far a set of recorded $x_{i}$ - derived from a set of identical samples constituted by $n$ drawn particles- are spread out from the expected value $\mu$ ):

$\mu=n p$

$\sigma^{2}=n p(1-p)$

Consequently, each sample (intended as $\mathrm{n}$ collected particles) is characterized by a specific $\dot{p}_{i}=x_{i} / n$, which is the estimator of $p$ in the sample itself. By definition, the more $p_{i}$ will resemble $p$, the more representative of the lot will be the collected sample.

The resulting squared coefficient of variation $\mathrm{CV}_{\mathrm{p}}{ }^{2}$ (also known as Relative Standard Deviation) is therefore

$C V_{p}^{2}=\frac{\sigma^{2}}{\mu^{2}}=\frac{n p(1-p)}{n^{2} p^{2}}=\frac{(1-p)}{n p}$

Here, $\mathrm{CV}_{\mathrm{p}}$ is the coefficient of variation indirectly identifying the extent of variability between different $\hat{p}_{i}$, observed on a set of identical samples, in relation to the true value p. In other words, the lower the $\mathrm{CV}_{\mathrm{p}}$, the more $\mathrm{p}_{\mathrm{i}}$ will resemble $p$, i.e., the more representative will be the collected samples. In particular, as $\mathrm{CV}_{\mathrm{p}}$ decreases with increasing $\mathrm{n}$, the exact value of $p$ can only be more and more precisely approached in samples containing higher and higher numbers of particles.

Finally, from Equation 4 we can derive $n$, the number of particles constituting the sample characterized by a fraction $\dot{p}_{i}$ of particles of interests, as:

$n=\frac{(1-p)}{C V_{p}^{2} p}$

Indeed, the calculation needed to estimate $\mathrm{n}$ is therefore based on the values of the parameters $p$ and $\mathrm{CV}_{\mathrm{p}}$, 
which must be known, measured or assumed for the lot to be characterized.

\subsection{Practical implications: meaning of $\mathrm{p}$ and $\mathrm{CV}_{\mathrm{p}}$ in granular waste}

Notably, Equation 5 is incorporated in the equations indicated in the technical standards giving the mass of the laboratory or test samples for wastes (i.e., CEN/TR 153101, 2007; EN 15002, 2015).

In the cited standards, $\mathrm{p}$ is defined as the "fraction of particles with a specific characteristic" (CEN/TR 15310-1, 2007) or "fraction of the particles with the property of interest" (EN 15002, 2015), this latter being the sole referring to the concept of "number of particles" in the lot with the characteristic of interest which should be present in a representative sample with the same proportion.

To achieve this goal, granular waste lots are conceptually modelled as a population of particles, each one showing or not a given property of interest. This latter can be defined as a chemical concentration, geometrical size (i.e., granulometry) or generic quality occurring in the $\mathrm{X}$-th percentile of the population to be analysed. In the waste field, particles with the "property of interest" are often intended as being characterized by a chemical concentration (e.g., trace elements, PolyAromatic Hydrocarbons, Flame Retardants, etc.), which is seldom $100 \%$ on the particle weight base. The concentration of constituents in a waste particle is rather a continuous function from the limit of quantification to the maximum, depending on the genesis of the particle (i.e., from solid fractionation, multi-mineral solid fraction, massive precipitation, surface precipitation, surface complexation, particles aggregation, etc.). Consequently, continuous variables such as chemical contents are conceptually transformed into a binary property defined by the sampler: e.g., each particle could or could not be characterized by a chemical concentration greater than an arbitrary value.

Given this background, the measured value of a characteristic of interest in a sample of granular solid waste (but this could be valid also beyond the sole waste field) can be assumed as the mean value of that characteristic as measured between all the particles making up the sample. Therefore, knowing or assuming how it is distributed within particles in the lot is crucial. If the distribution of concentrations among particles can be considered normal, as it is the case for industrial products, the last centiles are much less concentrated relatively to the mean, and their contribution is less critical. This implies that, where all particles making up the lot to be analysed contain almost the same individual concentration of the measurand, $p$ can be set to 1. Therefore, sampling and analysing one single particle would be enough.

On the contrary, where the properties of interest are characterized by distributions skewed by some highly concentrated and rare particles (i.e., 10 to 100 times the mean), up to the "nugget" distribution (e.g., one $100 \%$ particle in thousands or millions of $0 \%$ particles), the fraction of these "rare" particles collected in the sample will enormously affect the mean concentration measured, finally determin- ing the reliability (or, better, the representativeness) of the measured data. These latter conditions are the more expected in the waste field, where particles composition is usually not generated under controlled design criteria, as instead happens for industrial production. In these cases, p should be assumed much lower than the unity: this is reflected in EN 15002, which suggests using 0.1 to 0.001 , respectively for parameters of interest present at a "major" (e.g., dry matter) or "minor" (e.g., trace metals) level in the sample.

The coefficient of variation $\mathrm{CV}_{\mathrm{p}}$ is referred by the standards solely by using the term $\mathrm{CV}$ (i.e., without explicit mention to the relationship with $\dot{p}_{i}$ ) and defined as "the desired coefficient of variation caused by the fundamental error". The fundamental error is not further defined, but well the fundamental variability as "the inherent variability shown by a material and its analysis at the smallest scale of measurement". The expression "fundamental error" of the standard could result quite confusing, as it just implicitly refers to the "fundamental sampling error" of the TOS (Gy, 2004a; 2004b; 2004c; 2004d), whose calculation in the waste field is seldom performed, being based on many assumed parameters, not easily measurable as operational factors.

However, the standards likely suggest assuming CV (or $\mathrm{CV}_{\mathrm{p}}$, equivalently) as due to the analytical variability obtained with the smallest possible ("homogeneous") test portion in the same laboratory by the same operator, i.e., under "repeatability" conditions. Lower variability can simply not be obtained: in other words, a higher degree of representativeness cannot be provided by the sample. The minimum measurable $\mathrm{CV}$ is thus simply fixed to the $\mathrm{CV}_{\mathrm{r}}$ defined as the lowest variability that can be achieved only due to material heterogeneity and analysis variability at the lowest scale of measuring (i.e., matching with the definition of the fundamental variability):

$\min \left(C V_{p} \approx C V\right)=C V_{r}=0.1$

The value of $\mathrm{CV}_{r}$ for specifical analytical protocols are routinely measured in laboratories as part of their quality control system. For the sake of sampling, in CEN/TR 15310-1 and EN 15002, it is simply suggested to generally use CV $=0.1$ as respectively "well accepted value" or "typical value", without further explanations (as assumed by the authors and stated in Equation 6).

In the normal distribution, given the mean $x$ and the standard deviation $\mathrm{s}$, the confidence interval of the mean (i.e., covering $95 \%$ of the data set) is the interval $[x-1.96 \mathrm{~s}$ $; x+1.96 \mathrm{~s}$ ] or equivalently $\left[\mathrm{x}-1.96 \mathrm{CV}^{*} \mathrm{x} ; \mathrm{x}+1.96 \mathrm{CV}^{*} \mathrm{x}\right]$, which can be rounded to $x \pm 2 \mathrm{CV}^{*} \mathrm{x}$. By applying Equation 2 , the confidence interval of the estimator of $p$ obtained by repeated sampling of samples (which is a normal distribution ) is $\dot{p}_{i} \pm 0.2 \dot{p}_{i}\left(\right.$ or $\left.\dot{p}_{i} \pm 20 \%\right)$.

\subsection{From the number of particles to the mass of a representative sample}

As $p$ can be assumed $\ll<1$ for waste, and according to Equation 6, Equation 5 can be rearranged as:

$n p=\frac{(1-p)}{C V_{p}^{2}} \approx \frac{1}{C V_{r}^{2}} \approx 100$ 
In Equation 7, $\mathrm{np}$ is the "number of particles showing the property of interest" that must be in a representative sample. Equation 7 simply demonstrates that the hypothetical number of particles of interest in a representative sample is 100 , whatever $p$ is. This result is called the "number of target particles" by Bunge (2019) and was a conclusion from the same author (starting from another approach) and confirmed empirically (Bunge and Bunge 1999). Otherwise, the other extremely simple conclusion is that a representative sample must contain a total number $n$ of $100 / p$ particles, without assumptions on concentrations and size. It must be noted that in cases where $\mathrm{p}$ cannot be considered $\ll<1$ (e.g., chemical waste macrocomponents, general waste material fractions, etc.), the simplified formula of Equation 7 will determine higher number of particles than the sole Equation 5 and thus it can be considered as a conservative approach (i.e., leading to samples characterized by higher $\mathrm{n}$ ).

Furthermore, Equation 7 is based on the theoretical variability imposed in terms of $\mathrm{CV}_{\mathrm{r}}$ : here, assuming a larger variability in the results (i.e., $\mathrm{CV}_{r}>0.1$ ) will lead to fewer particles in in the sample (as can be easily recalculated from Equation 7) together with a consequent lower degree of sample representativeness. In other words, samples containing less than 100 particles of interest could lead to a higher uncertainty/variability associated with the measurement of the parameter of interest.

As previously introduced, in the horizontal standards for waste sampling and test portions preparation from laboratory samples (CEN/TR 15310-1, (2007) and EN 15002, (2015), extended with the f factor in EN 15413, (2011) for solid recovered fuel), Equation 5 (therefore also Equation 7) results incorporated in the equation giving the mass of the laboratory sample or of the test portion:

$M_{\text {sam }}(k g)=\frac{\pi}{6}\left(D_{95}\right)^{3} * \rho_{\text {solid }} * g * f * \frac{(1-p)}{C V^{2} p}$

Where, D95 and D05 are respectively the 95th and 5th mass percentiles of particles diameters, $\rho_{\text {solid }}$ is the particles solid density, $\mathrm{g}$ is a correction factor for particle size distribution (for uniform distribution, i.e., D95/D05 $\leq 1, \mathrm{~g}=1$; for narrow distribution, i.e., $1<\mathrm{D} 95 / \mathrm{D} 05 \leq 2$, $g=0.75$; for medium distribution, i.e., $2<\mathrm{D} 95 / \mathrm{D} 05 \leq 4, \mathrm{~g}=0.5$; and for broad distribution, i.e., $4<\mathrm{D} 95 / \mathrm{D05}, \mathrm{g}=0.25$ ) and $\mathrm{f}$ is a form factor, defined as the ratio of the volume of the D95 particles as a multiple of their three dimensions, divided by the volume of a cube of D95 size. In this respect, Equation 8 allows to calculate the mass of the laboratory sample as the number $\mathrm{n}$ of particles needed in the sample i.e., (1$\mathrm{p}) /\left(\mathrm{CV}_{\mathrm{p}}{ }^{2} \mathrm{p}\right)$, multiplied by the mean mass of particles (i.e., $\left.\pi / 6\left(D_{95}\right)^{3 *} \rho_{\text {solid }}{ }^{*} g^{\star} f\right)$, approximated as the mass of a sphere with the diameter of the largest particles averaged among the particle size distribution. In particular, the $\mathrm{g}$ factor takes partially into account the fact that many particles are finer than D95, while the f factor is used to have a more realistic approach of the volume of the large particles (EN 15413, 2011).

In this context, it should finally be highlighted that the standards used for waste sampling introduce a further requirement, needed to avoid particle segregation during practical sampling performance. This comes from the fact that the use of the binomial probability distribution to model sampling is justified only if each sampling action can be considered probabilistic, i.e., each particle is characterized by a uniform non-zero probability to be caught. This condition is included in the definition of correct sampling given by Gy (2004a), as mandatory to derive reliable (i.e., representative) samples.

In practice, individual samples are the result of several extractions of equivalent increments, considered as a subset of neighbouring particles of the lot. In this regard, we can interpret the requirements laid down in the standard CEN/TR 15310-1, (2007), which are i) on the actual size of the sampling instrument (i.e., width, height and length must be at least 3 times the size of the largest particles) and ii) on the consequent minimum increment mass $M_{\text {inc }}$ (Equation 9), as conditions to perform probabilistic sampling and avoid large particles segregation:

$M_{\text {inc }}=\left(3 * D_{95}\right)^{3 *} \rho_{\text {bulk }}$

where D95 is the 95-percentile particle diameter and $\rho_{\text {bulk }}$ the bulk density of the material. It must be kept in mind that Equation 8 and Equation 9 are only approximations.

\subsection{Estimation of $p$ for some granular waste for compliance assessment}

The fraction of highly concentrated particles of interest (p) that must not be exceeded in waste to not trespass a concentration limit (CL), intended as the mean concentration among all particles, can be calculated from the functional concentration (FC) of the analyte in the products that became waste. Here, a CL is a concentration that must not be exceeded for compliance with waste regulation or (secondary) product specifications. In this respect, the particles of interest can be assumed as those with the recommended FC. FC can be found in producer's catalogue and in technical literature or product safety data sheets.

Consequently, if the other particles of the lot have a null concentration and all particles are characterized approximately by the same mass, the mean concentration of the lot of particles is equal to $\mathrm{pFC}+(1-\mathrm{p}) 0=\mathrm{pFC}$. That concentration must be lower or equal to the $\mathrm{CL}$, thus leading to $\mathrm{pFC} \leq \mathrm{CL}$ or $\mathrm{p} \leq \mathrm{CL} / \mathrm{FC}$. Therefore, the fraction of particles of interest is simply lower or equal to the ratio of the $C L$ in waste and the FC in products.

Indeed, this approach is limited to waste originating from products with a known composition, and with all the particles having approximately the same mass (e.g., plastic scraps after shredding). Examples are additives of fire-protected plastics: the CL for the persistent organic pollutants polybromodiphenylethers (PBDEs), the hexabromocyclododecane (HBCDD) and the short-chain chlorinated paraffins (SCCPs) under consideration are $200 \mathrm{mg} \mathrm{kg}^{-1}$, $100 \mathrm{mg} \mathrm{kg}^{-1}$ and $540 \mathrm{mg} \mathrm{kg}^{-1}$, respectively. As their maximal reported FC are $180,000 \mathrm{mg} \mathrm{kg}^{-1}, 40,000 \mathrm{mg} \mathrm{kg}^{-1}$ and 30,000 $\mathrm{mg} \mathrm{kg}^{-1}$, respectively, the samples must be large enough to capture particles with a frequency of $p=C L / F C=0.0011$, 0.0025 and 0.0140 . In other words, 11 particles with a concentration of $180,000 \mathrm{mgPBDE} \mathrm{kg}^{-1}$ and 9989 particles with 
a zero concentration have a mean concentration of 200 mgPBDE $\mathrm{kg}^{-1}$, which is the concentration that a representative sample must be able to measure for compliance assessment, here with a relative variability of $10 \%$ when the sampling and analysis operations are repeated. The corresponding $\mathrm{n}$ for the three cases above $=100 / \mathrm{p}=100,000$, 40,000 and 7,000 particles (Vencovski et al. 2021).

\section{MATERIALS AND METHODS}

For the aim of this study, three types of data or information were collected from published documents in the scientific or technical literature and here used for three different analyses.

\subsection{Assessment of concentration distributions at particle scale}

First, single particle concentrations of $\mathrm{Br}$ were collected from Hennebert, (2020) as analyzed through portable $\mathrm{XRF}$, calibrated with reference material for $\mathrm{Br}$, on three samples of plastic scraps originated from shredding of waste from electric and electronic equipment (WEEE). The first sample was composed by a total of 200 particles and was collected immediately after shredding of one lot of WEEE; the second, counting 200 particles, was sampled after shredding and further density sorting (usually applied to sort out the denser brominated scraps). The third sample consists on 350 sorted dense plastic scraps from waste of cathode ray tubes (CRD). Descriptive statistics (mean, median, maximum value, standard deviation and $\mathrm{CV}$ ) was performed on the collected single particles concentrations of $\mathrm{Br}$ from the considered samples. Further, histograms were built for datasets together with cumulated histograms to graphically summarize the occurring distributions among the collected particles concentrations. All statistical work and graphical representations were performed using $\mathrm{Mi}$ crosoft Excelß 2016.

\subsection{Assessment of the observed variability at ana- lytical scale}

Then, data on observed CVs were collected as calculated from 6 sets of analytical results obtained by the performance of different analytical methods (i.e., measuring different parameters) applied to specific materials:

- $\mathrm{Br}$ and Sb concentrations obtained from repeated XRF analysis performed by the authors on a certified reference plastic material;

- Elemental and Brominated Flame Retardants (BFR) concentration determined through Ion Chromatography (IC) on certified reference plastic material (Haarman et al. 2018);

- $\mathrm{Br}$ and $\mathrm{Sb}$ concentrations derived through IC and Inductively Coupled Plasma (ICP) analysis performed on laboratory samples of plastics from small household appliances (SHA) and screens (Hennebert and Filella 2018);

- Concentrations of Polyaromatic hydrocarbons (PAH), Polychlorobiphenyls (PCB) and Dioxins (PCDD/PCDF) derived from an intra and inter-laboratory ring test validating the related methods EN 16181, (2018), EN 16167, (2018) and EN 16190 applied on samples of sludge, compost and soil (Kalbe et al., 2019);

- Elements concentrations determined through ICP and IC on water extracts derived from standardized leaching tests applied on waste materials and presented as validation data in the dedicated technical standard (EN 12457-2, (2002));

- Results from ecotoxicological bioassays involving different organisms (marine bacteria, freshwater algae, soil bacteria and earthworms) performed on reference test media (i.e., liquid or solid media spiked with known concentration of contaminants), proposed for assessment of the hazard property HP 14 of waste (Pandard and Roembke 2013, Hennebert 2018) (EN ISO 113483, (2008), EN ISO 8692, (2012), ISO 18187, (2018), ISO 17512-1, (2020)).

The collected data on analytical CVs were first used to compare the achievable inter-laboratory and intra-laboratory variability by the considered different analytical methods. These results were then used to assess the reliability of the assumption made on the value of the $\mathrm{CV}_{r}$ in Equation 6 to derive the requirement on the needed number of particles of interest in a representative sample (i.e., Equation 7).

\subsection{Assessment of number of particles in laboratory samples and test portions}

The values of size (mass or volume) of samples were collected as indicated in 6 sampling plans, designed for different waste materials, and already published in technical reports or standards. The main general instructions are described as follows:

- Waste wood from furnitures. Increments of $5 \mathrm{~m}^{3}$ are taken. Their number is $20+0.06$ times the mass of the batch (in tons). This composite sample is shredded on site and sieved in two fractions ( $80-15 \mathrm{~mm}$, and $<15 \mathrm{~mm}$ ). Each fraction is sampled in order to make a laboratory sample of $2 \mathrm{kgs}$ (Eco-Mobilier and Valdelia, 2018);

- French municipal solid waste incinerator bottom ashes (both maturated and un-maturated). Six to one hundred increments of 10 liters are taken, mixed and quartered until a laboratory sample of 2 to $8 \mathrm{~kg}$ is obtained (SVDU, 1995);

- Shredded plastics of WEEE from SHA (Wäger et al. 2011);

- Shredded plastics of WEEE from SHA (CENELEC TS 50625-3-1, (2015));

- Waste from plastic lamps (CLC/TS 50625-3-2, 2016);

- WEEE plastic scraps (Maris et al. 2015).

Finally, the values of size (mass or volume) of test portions were gathered from 7 among the most used analytical standards for waste characterization: waste percolation test EN 14405, (2017), granular waste leaching test EN 12457 parts 1-4, (2002), XRF elemental analysis EN 15309, (2007), waste acid digestion for subsequent determination of elements EN 13656, (2020), PCB analysis in waste EN 
15308, (2017), Polybrominated biphenyls and polybrominated diphenyl ethers analysis in polymers of products EN 62321-6, (2015) and waste EN 16377, (2013).

The reported sample sizes were then analysed to assess the number of particles present in the samples themselves. Where granulometric and physical information were available in the cited reference, number of particles were calculated as follows (according to Equation 8):

$n=\frac{M_{s p}}{\frac{\pi}{6}\left(D_{95}\right)^{3} \rho_{\text {solid }} * g * f}$

Where $\mathrm{n}$ is the number of particles in the sample, $M_{s p}$ is the mass $(\mathrm{kg})$ of sample as indicated in the published sampling plan or test portion preparation standard, while the definitions of $D_{95}, \rho_{\text {solid }}, g$ and $f$ are the same used for Equation 8. However, not all considered references reported in detail the needed information on these latter parameters. In these cases, authors or professional unions related with the management of the specific waste material were contacted to collect (or estimate, based on personnel's experience) the missing information.

\section{RESULTS AND DISCUSSION}

\subsection{Observed distribution of concentrations at par- ticle scale}

Three examples of single particles concentrations of $\mathrm{Br}$ in WEEE are presented in Figure 1 (Hennebert, 2020): at first sight, the normal distribution does not fit with the data.

Data of Br concentration from plastic scraps after shredder were characterized by median value of $5 \mathrm{mg} / \mathrm{kg}$, a mean of $3,536 \mathrm{mg} \mathrm{Br} \mathrm{kg}^{-1}$, a maximum value of $139,300 \mathrm{mg} \mathrm{Br} \mathrm{kg}^{-1}$, a standard deviation of $=16,968 \mathrm{mg} \mathrm{Br} \mathrm{kg}^{-1}$ and a CV of 4.80 . Furthermore, shredded WEEE plastic particles undergone density sorting showed a median value of $8 \mathrm{mg} \mathrm{Br} \mathrm{kg}^{-1}$, a mean of $995 \mathrm{mg} \mathrm{Br} \mathrm{kg}^{-1}$, max $=31,664 \mathrm{mg} \mathrm{Br} \mathrm{kg}^{-1}$, a standard deviation of $4,683 \mathrm{mg} / \mathrm{kg}$ and a CV of 4.70 ) (Hennebert, 2020). Accordingly, the last percentiles tremendously influence the mean concentration. The median and the mean are in fact very different.

The normal distribution underestimates the contribution of the last centiles to the mean. For instance, among the 200 measured $\mathrm{Br}$ concentrations in shredded plastic particles, the two more concentrated particles increase the mean concentration of $1,000 \mathrm{mg} \mathrm{Br} \mathrm{kg}^{-1}$ and represent about $25 \%$ of the total bromine present in the batch of particles. Here, by considering also the trivial hypothetical case of 999 particles with $0 \mathrm{mg} \mathrm{Br} \mathrm{kg}{ }^{-1}$ and one particle with $100,000 \mathrm{mg} \mathrm{Br} \mathrm{kg}^{-1}$ resulting in a mean concentration of $100 \mathrm{mg} \mathrm{Br} \mathrm{kg}^{-1}$, the measured data clearly suggest that these few particles must absolutely be "captured" (be present) in a representative laboratory sample. If they are not (if there are not "enough" particles of interest in the sample), different laboratory samples will give highly variable mean concentration per sample (as measured in the laboratory). Also, the concentration of individual particles cannot be predicted with mean and standard deviation, as usual, with the normal distribution.

Sometimes the distribution is trimodal, as exemplified in the bromine concentration of sorted dense plastic scrap of cathode ray tubes (Figure 1). There are three groups of concentration that can be observed in Figure 1: $<1000 \mathrm{mg}$ $\mathrm{Br} \mathrm{kg}$ (no bromine, but probably other additives used to increase density of the plastic), 15,000-45,000 mg Br kg-1 (insufficient concentration for fire protection, probably the result of improper recycling), and 50,000-150,000 $\mathrm{mg} \mathrm{Br}$ $\mathrm{kg}^{-1}$ (fire protected plastics). It should be noted that such skewed distributions are frequently observed at population scales. This point is briefly mentioned here because it is not the topic of this paper, dealing with particle scale.

\subsection{Observed analytical variability}

In Equation 6, $\mathrm{CV}_{\mathrm{p}}$ is assumed equal as $\mathrm{CV}_{\mathrm{r}}$, which is the variability of the measurement at the smallest analytical scale (on the smallest test portion that can be analyzed). This paragraph discusses the collected data of several $\mathrm{CV}_{\mathrm{r}}$ with granular solid waste, to assess the reliability of this assumption.

Results from the collection of variability values are presented in Table 1. Here, two cases are distinguished: analysis without extraction (e.g., direct analysis like XRF or direct analysis of liquid extracts), and extraction followed by the analysis (i.e., typical analysis performed for solid materials). The analytical variability of homogeneous liquid samples or liquid extracts of solid waste is well known as "low" (typically $\mathrm{CV}_{\mathrm{r}} \approx 0.03$ ). The variability of analysis involving extraction from solids is higher. For the measurement of the total content (of element or substance), the extraction is done under extreme conditions (fine powder, acids or base, solvent, high temperature, etc.), potentially until the total dissolution of the solid matrix, which can be easily verified by the analyst. These strong conditions guarantee that total extraction occurs. But regarding the measurement of partial content of element or substance (like leaching tests, percolation tests, (bio)available concentrations...), the extraction is done under milder conditions (coarser particles or aggregates, deionized water or mild extractant like EDTA or sodium dithionite, room temperature, mild solid/liquid separation at the end of the extraction, etc.). The extraction must follow exactly the protocol, and the protocol itself should not have variants; otherwise the extraction ratio could be higher or lower. Due to this two-step-procedure, and since partial extraction is more variable, the analytical variability of solid samples is typically higher than the one of liquids.

The intra-laboratory variability (repeatability) of chemical (total) analysis is low: the specific resulting mean is 0.04 for analysis without extraction, and 0.10 with extraction (light green cells). The inter-laboratory variability (reproducibility) of chemical analysis of reference material or prepared "homogeneous" samples is (logically) higher: here, the mean CV is 0.21 for analysis without extraction, and 0.24 with extraction (light orange cells).

Leaching tests and biotests have higher variability. It should be noted that they make use of only partial extractions (i.e., of the leaching fraction or the bioavailable fraction), more sensitive to changes of results when the methods are not strictly followed. For leaching tests (EN 12457-2), the variability of inter-laboratory tests of prepared solid samples is clearly higher $(\mathrm{CV}=0.37$ ) (yellow cell). In this respect, the inter-laboratory variability could 

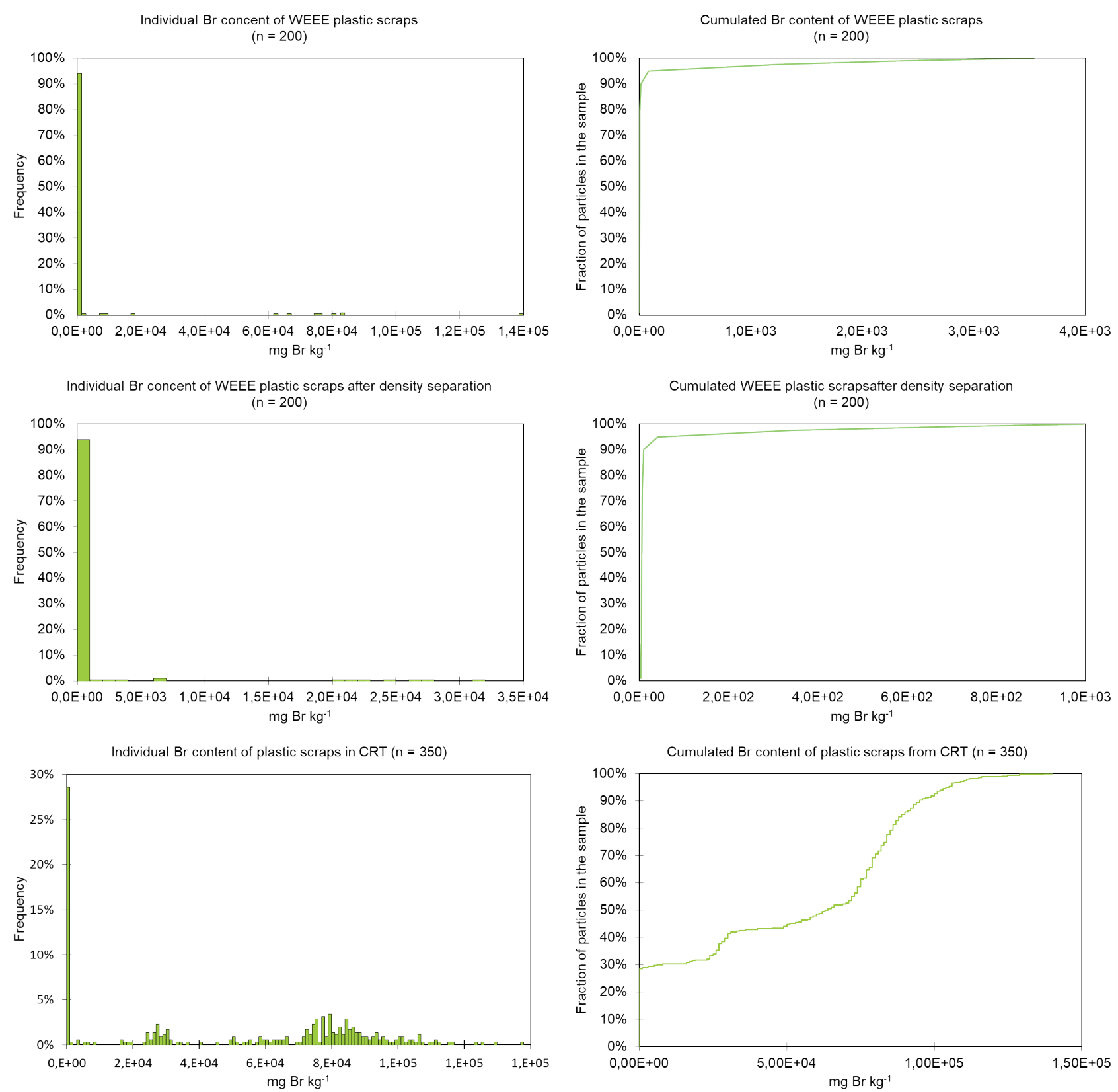

FIGURE 1: Histograms of $\mathrm{Br}$ particles concentrations (left) and cumulated mean $\mathrm{Br}$ concentration (right) in samples of in WEEE plastic scraps before (top) and after density separation (middle) and in plastic scraps from CRT (bottom).

originate from the different options available in the standard for liquid-solid contact (e.g., rolling, tumbling, etc.) and liquid-solid separation (e.g., decantation, filtration, centrifugation), that should instead be fixed in the standard to reduce the inter-laboratory variability. The influence of all these parameters was discussed with the results from an inter-laboratory test (Van der Sloot et al. 2001).

Only data of biotests whose related technical standard provides validation data were considered (Table 1). The CVs are calculated from the intra-laboratory variability on one reference substance ( 1 spiked solid media), and the inter-laboratory variability on prepared matrices (2 liquid solutions and 1 spiked solid media). However, the variability could be calculated only from intra-laboratory repetitions (i.e., CV of 0.20 ). There are not enough data of inter-laboratory trials on true waste samples in the standards, including sample preparation and leaching for the aquatic tests on solid leachates, to calculate a representative CV for inter-laboratory variability.

In summary, possible reasons are resumed in Table 2 explaining the (too high) CVs observed in Table 1.

\subsection{Number of particles in samples and subsamples}

\subsubsection{Laboratory samples}

Six cases of sampling plan from technical reports or standards (i.e., present in the data section) are compared with the optimal size of a representative sample, as expressed as $\mathrm{n}$ in Equation 7, (Table 3). For waste wood 
TABLE 1: Observed CVs in results from the performance of different analytical methods on sets of samples of different materials. Light green: $C V \leq 0.10$, green: $C V \leq 0.20$, light yellow: $C V \leq 0.30$, yellow; $C V>0.30$

\begin{tabular}{|c|c|c|c|c|c|c|c|c|c|c|c|c|c|c|c|}
\hline \multirow{3}{*}{ Sample } & \multirow{3}{*}{ Reference } & \multirow{3}{*}{$\begin{array}{l}\text { Target } \\
\text { Parameters }\end{array}$} & \multirow{3}{*}{ Methods } & \multicolumn{6}{|c|}{ Intra-laboratory } & \multicolumn{6}{|c|}{ Inter-laboratory } \\
\hline & & & & \multicolumn{3}{|c|}{$\begin{array}{l}\text { Analysis (no } \\
\text { extraction) }\end{array}$} & \multicolumn{3}{|c|}{$\begin{array}{l}\text { Analysis (with } \\
\text { extraction) }\end{array}$} & \multicolumn{3}{|c|}{$\begin{array}{l}\text { Analysis (no } \\
\text { extraction) }\end{array}$} & \multicolumn{3}{|c|}{$\begin{array}{l}\text { Analysis (with } \\
\text { extraction) }\end{array}$} \\
\hline & & & & $=$ & $\begin{array}{l}\text { 『్ } \\
\text { छ๊ } \\
\text { 己े }\end{array}$ & 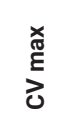 & $=$ & $\begin{array}{l}\text { ॠ } \\
\stackrel{\Xi}{\Xi} \\
\text { 己े }\end{array}$ & 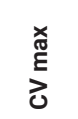 & $=$ & 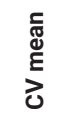 & 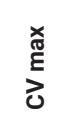 & $=$ & 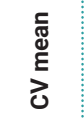 & $\begin{array}{l}\stackrel{x}{\widetilde{m}} \\
\text { d }\end{array}$ \\
\hline \multirow{2}{*}{$\begin{array}{l}\text { Plastic } \\
\text { reference } \\
\text { material }\end{array}$} & \multirow{2}{*}{$\begin{array}{l}\text { Original } \\
\text { data }\end{array}$} & $\mathrm{Br}$ & XRF & 25 & 0.01 & & & & & & & & & & \\
\hline & & $\mathrm{Sb}$ & XRF & 25 & 0.03 & & & & & & & & & & \\
\hline \multirow{2}{*}{$\begin{array}{l}\text { Plastic } \\
\text { reference } \\
\text { material }\end{array}$} & \multirow{2}{*}{$\begin{array}{l}\text { Haarman } \\
\text { et al. } 2018\end{array}$} & Elements & $\begin{array}{l}\text { Combus- } \\
\text { tion, IC }\end{array}$ & & & & & & & & & & n.a.* & $0.06^{*}$ & $0.13^{*}$ \\
\hline & & BFR & EN 62321-6 & & & & & & & & & & 12 & 0.20 & 0.36 \\
\hline \multirow{4}{*}{$\begin{array}{l}\text { Plastic } \\
\text { scraps } \\
\text { from } \\
\text { SHA and } \\
\text { screens }\end{array}$} & \multirow{4}{*}{$\begin{array}{l}\text { Hennebert } \\
\text { and Filella } \\
2018\end{array}$} & $\mathrm{Br}$ & $\begin{array}{l}\text { Combus- } \\
\text { tion, IC }\end{array}$ & & & & $33 t$ & 0.10 & 0.27 & & & & & & \\
\hline & & $\mathrm{Sb}$ & $\begin{array}{l}\text { Combus- } \\
\text { tion, ICP }\end{array}$ & & & & $33 \mathrm{t}$ & 0.10 & 0.25 & & & & & & \\
\hline & & BFR & EN 62321-6 & & & & $178 t$ & 0.16 & 0.64 & & & & & & \\
\hline & & All & & & & & $244 t$ & 0.14 & 0.64 & & & & & & \\
\hline \multirow{6}{*}{$\begin{array}{l}\text { Sludge, } \\
\text { compost } \\
\text { and soil }\end{array}$} & \multirow{6}{*}{$\begin{array}{l}\text { Kalbe et } \\
\text { al. } 2019\end{array}$} & $\mathrm{PAH}$ & EN 16181 & 31 & 0.04 & 0.08 & 75 & 0.10 & 0.17 & 31 & 0.15 & 0.34 & 75 & 0.39 & 1.23 \\
\hline & & PCB & EN 16167 & 77 & 0.07 & 0.09 & 76 & 0.06 & 0.09 & 77 & 0.32 & 0.38 & 76 & 0.27 & 0.39 \\
\hline & & $\begin{array}{l}\text { PCDD/ } \\
\text { PCDF/PCB- } \\
\text { DL }\end{array}$ & EN 16190 & 27 & 0.07 & 0.20 & 31 & 0.09 & 0.66 & 27 & 0.25 & 0.40 & 31 & 0.25 & 1.38 \\
\hline & & $\Sigma \mathrm{PAH}$ & EN 16181 & 26 & 0.03 & 0.04 & 82 & 0.06 & 0.07 & 26 & 0.12 & 0.20 & 82 & 0.30 & 0.35 \\
\hline & & $\Sigma \mathrm{PCB}$ & EN 16167 & 77 & 0.06 & 0.06 & 78 & 0.05 & 0.06 & 77 & 0.23 & 0.23 & 78 & 0.21 & 0.23 \\
\hline & & $\begin{array}{l}\text { \PCDD/ } \\
\text { PCDF }\end{array}$ & EN 16190 & & & & 33 & 0.06 & 0.08 & & & & 33 & 0.13 & 0.17 \\
\hline $\begin{array}{l}\text { Waste } \\
\text { solid } \\
\text { samples }\end{array}$ & $\begin{array}{l}\text { Method } \\
\text { validation } \\
\text { data }\end{array}$ & Elements & EN 12457-2 & 38 & 0.04 & 0.24 & 38 & 0.17 & 0.77 & & & & 38 & 0.37 & 1.1 \\
\hline $\begin{array}{l}\text { Reference } \\
\text { material } \\
\text { (liquid and } \\
\text { solid) }\end{array}$ & $\begin{array}{l}\text { Method } \\
\text { validation } \\
\text { data }\end{array}$ & $\mathrm{EC}_{50}$ & $\begin{array}{l}\text { EN ISO } \\
11348-3 \\
\text { EN ISO } \\
8692 \\
\text { ISO } 18187 \\
\text { ISO 17512- } \\
1\end{array}$ & & & & $\begin{array}{l}8(1 \\
\text { test })\end{array}$ & 0.20 & 0.38 & $\begin{array}{l}17(3 \\
\text { tests })\end{array}$ & 0.25 & 0.39 & & & \\
\hline
\end{tabular}

TABLE 2: Possible causes of reported high CVs in intra- and inter-laboratory measurements performed on laboratory samples or test portions, with identification of cases when the analysis should be improved, and cases when the sampling should be improved.

\begin{tabular}{|c|c|c|c|c|c|}
\hline \multirow{2}{*}{$\begin{array}{l}\text { Type of Variability } \\
\text { Sample }\end{array}$} & \multicolumn{3}{|c|}{ Intra-laboratory - Repeatability } & \multicolumn{2}{|c|}{ Inter-laboratory - Reproducibility } \\
\hline & $\begin{array}{l}\text { "Homogeneous" sam- } \\
\text { ples (liquid or solid) }\end{array}$ & $\begin{array}{c}\text { Prepared test portions } \\
\text { from a laboratory } \\
\text { sample }\end{array}$ & $\begin{array}{l}\text { Set of identical labora- } \\
\text { tory samples }\end{array}$ & $\begin{array}{c}\text { Prepared test portions } \\
\text { from a laboratory } \\
\text { sample }\end{array}$ & $\begin{array}{l}\text { Set of identical labora- } \\
\text { tory samples }\end{array}$ \\
\hline $\begin{array}{l}\text { Analysis (no } \\
\text { extraction) }\end{array}$ & CV > 0.10 (High) & $C V<0.10$ & $C V<0.10$ & - & - \\
\hline $\begin{array}{l}\text { Extraction and } \\
\text { analysis }\end{array}$ & - & CV > 0.20 (High) & CV > 0.20 (High) & CV > 0.25 (High) & CV > 0.25 (High) \\
\hline $\begin{array}{l}\text { Causes and } \\
\text { improvements }\end{array}$ & $\begin{array}{l}\text { Improve the analysis } \\
\text { methods in the labo- } \\
\text { ratory }\end{array}$ & $\begin{array}{l}\text { Improve the extraction } \\
\text { methods in the labo- } \\
\text { ratory }\end{array}$ & $\begin{array}{l}\text { Check if the laboratory } \\
\text { samples or test por- } \\
\text { tions contain "enough" } \\
\text { particles }\end{array}$ & $\begin{array}{l}\text { Check and minimize } \\
\text { the variations in the } \\
\text { practical procedures } \\
\text { allowed between labo- } \\
\text { ratories by the technical } \\
\text { standards }\end{array}$ & $\begin{array}{l}\text { Check if the labora- } \\
\text { tory samples contain } \\
\text { "enough" particles }\end{array}$ \\
\hline
\end{tabular}

from furniture and MSWI bottom ashes, the mean mass of particles was estimated respectively from data provided by CEDEN, the consulting company of Valdelia and Eco-Mobilier, and SVDU, this latter referring to unbound mixtures for roadwork platforms granulometry. For both samples of plastic shreds from SHA, it is estimated according original laboratory data (Wäger et al. 2011, CENELEC TS 50625-3-1, (2015)). The number of particles in the sample is given by the authors for WEEE Plastic scraps (Maris et al., 2015). 
For wood coming from construction and demolition waste and furniture, the estimated corresponding number of particles in the laboratory sample using a mean particle mass is large, according to the authors of the study (i.e., 200,000 and 40,000 for the two considered lower size fractions). However, that number is calculated as insufficient (i.e., 33 for the $80-15 \mathrm{~mm}$ fraction) (Table 3).

For MSWI bottom ashes (Table 3), if fines occur in the sample (i.e., assuming low values for g), the calculated number of particles in the laboratory sample is large as well (greater than 100 million). Whether fines are not assumed present, that number is calculated as insufficient (165). Nevertheless, some (non-ferrous) metals are more concentrated in fractions of 1 to some millimetres, according to the literature (Chimenos et al 1999, Holm and Simon 2017) and to recovery practices that become widespread.

For plastics scraps of waste of electrical and electronic equipment (WEEE), a survey of RoHS regulated substances in WEEE plastic in Europe (Wäger et al. 2011) recommended a method for sampling, coming from LAGA (2001). The minimum volume and amount of single, mixed and laboratory sample for a total mixed plastics volume of maximally $30 \mathrm{~m}^{3}$ (from about 20 tons in one day production) is between 2 and $5 \mathrm{~kg}$, depending on size (Table 3). The corresponding $\mathrm{n}$ are probably too low and $\mathrm{p}$ are probably too high (between 0.09 and 0.20 ). This could mean that the rare "POP-concentrated" particles can be captured or not, randomly. Repeated samples will give (sometimes or not,indeed randomly...) different results, as observed by the authors (i.e., difference close to one order of magnitude for TBBPA, OctaDBE, and DecaBDE).
For plastic scraps of WEEE, according to technical specifications CENELEC TS 50625 3-1, (2015), the size of the laboratory sample is 7.5 to 25 litres for SHA, and 1 litre for fluorescent lamps. For SHA, the number of particles present in the laboratory samples of 7.5 to 25 litres (depending on the size of the plastic scraps) is calculated as 800-1 000, with corresponding $p$ as $0.09-0.10$. For shredded fluorescent lamp plastics, the values of $p$ are calculated as 0.25 to 0.73 . These $p$ values must be verified for these plastics but are probably not unrealistic for the unsorted fraction. Plastics from SHA are largely brominated (Hennebert and Filella 2018) and plastic waste from fluorescent lamps are most often brominated (personal communication from the French organization of extended producer responsibility), indicating that most or all those wastes are brominated (i.e., p approaches 1).

At the contrary, for the sorted fractions of SHA for bromine in view of recycling (with as low as possible particles $<2,000 \mathrm{mg} \mathrm{Br} \mathrm{kg}^{-1}$ ), $\mathrm{p}$ can be estimated to 0.01 (Hennebert 2020), calculated $n$ is 10,000 , with corresponding masses of $20-80 \mathrm{~kg}$ and the corresponding volumes $60-240$ litres, clearly larger than the recommendation of the standard.

Finally, aiming at the identification of polymers in plastics (Maris et al. 2015), from batch of 10 tons, a composite sample of $9.3 \mathrm{~kg}$ of scraps (from 10 increments) is taken, sieved $>20 \mathrm{~mm}$ for characterization, and the resulting fraction of $5.5 \mathrm{~kg}$ is "acceptable by all of the project partners" as laboratory sample mass. It is constituted of about 1,500 particles as mentioned by the authors. With samples of 1,500 particles, only the particles of interest with a frequency $p \geq 0.06$ will be detected with a low variability. By

TABLE 3: Estimated number of particles ( $n$ ) in laboratory waste samples collected according to published sampling plans (Eq. 10). The fraction of rare particles of interest $(p)$ which can be assessed with a theoretical CV of 0.1 is calculated from Equation 7. $S_{\text {lot }}=$ Assumed usual size of the lot of waste to be sampled. $M_{\text {sam }}(\mathrm{kg})$ = mass of sample as indicated in the specific reference. For $D_{95}, \rho_{\text {solid }} g$ and $f$ refer to Eq. 10. * = the number of particles $\mathrm{n}$ was provided directly in the reference without any hypothesis.

\begin{tabular}{|c|c|c|c|c|c|c|c|}
\hline Sample & Reference & $\mathbf{S}_{\text {lot }}$ & $\mathrm{D}_{95}(\mathrm{~m})$ & $M_{\text {sam }}(\mathbf{k g})$ & $\frac{\pi}{6}\left(D_{95}\right)^{3} * \rho_{\text {sollid }} * g * f$ & $n$ & $p(C V=0.1)$ \\
\hline \multirow{3}{*}{$\begin{array}{l}\text { Waste wood from } \\
\text { furnitures }\end{array}$} & \multirow{3}{*}{$\begin{array}{l}\text { Eco-Mobilier and } \\
\text { Valdelia, } 2018\end{array}$} & \multirow[t]{3}{*}{$100-1,000$ tons } & $\mathrm{D}_{95}<0.015$ & 2 & 0.000010 & 200,000 & 0.0005 \\
\hline & & & 0.015 & 2 & 0.000050 & 40,000 & 0.002 \\
\hline & & & 0.080 & 2 & $6.0 \mathrm{E}-02$ & 33 & 0.751 \\
\hline \multirow{2}{*}{$\begin{array}{l}\text { MSWI bottom ash } \\
\text { (Un-maturated) }\end{array}$} & \multirow[t]{4}{*}{ SVDU, 1995} & \multirow{4}{*}{$\begin{array}{l}2,000-20,000 \\
\text { tons }\end{array}$} & $0.050,1 \%<63 \mu \mathrm{m}$ & 2 & $2.00 \mathrm{E}-08$ & $1.00 \mathrm{E}+08$ & 0.0000010 \\
\hline & & & $0.050,1 \%<63 \mu \mathrm{m}$ & 8 & $2.00 \mathrm{E}-08$ & $4.00 \mathrm{E}+08$ & 0.0000002 \\
\hline \multirow{2}{*}{$\begin{array}{l}\text { MSWI bottom ash } \\
\text { (Maturated) }\end{array}$} & & & $0.050,1 \%<63 \mu \mathrm{m}$ & 6.75 & $2.00 \mathrm{E}-08$ & $3.38 \mathrm{E}+08$ & 0.0000003 \\
\hline & & & 0.050, No fines & 6.75 & $4.1 \mathrm{E}-02$ & 165 & 0.377 \\
\hline \multirow{3}{*}{$\begin{array}{l}\text { Plastic shreds from } \\
\text { SHA }\end{array}$} & \multirow[t]{3}{*}{ Wäger et al 2011} & $30 \mathrm{~m}^{3}$ & $0.002<D_{95}<0.020$ & 2 & 0.002 & 1,000 & 0.091 \\
\hline & & $30 \mathrm{~m}^{3}$ & $0.020<D_{95}<0.050$ & 2 & 0.005 & 400 & 0.200 \\
\hline & & $30 \mathrm{~m}^{3}$ & $0.050<D_{95}<0.120$ & 5 & 0.010 & 500 & 0.167 \\
\hline \multirow{3}{*}{$\begin{array}{l}\text { Plastic shreds from } \\
\text { SHA }\end{array}$} & \multirow{3}{*}{$\begin{array}{l}\text { CENELEC TS } \\
50625 \text { 3-1 }\end{array}$} & Daily production & $\mathrm{D}_{95}<0.020$ & 2.2 & 0.002 & 1,080 & 0.085 \\
\hline & & Daily production & $0.020<D_{95}<0.050$ & 3.5 & 0.004 & 864 & 0.104 \\
\hline & & Daily production & $0.050<D_{95}<0.100$ & 7.2 & 0.008 & 900 & 0.100 \\
\hline \multirow{4}{*}{$\begin{array}{l}\text { Waste from plastic } \\
\text { lamps }\end{array}$} & \multirow[t]{4}{*}{ EN 50625-3-2 } & Daily production & $\mathrm{D}_{95}<0.005$ & 0.3 & 0.001 & 300 & 0.250 \\
\hline & & Daily production & $0.005<D_{95}<0.020$ & 0.3 & 0.002 & 150 & 0.400 \\
\hline & & Daily production & $0.020<D_{95}<0.050$ & 0.3 & 0.004 & 75 & 0.571 \\
\hline & & Daily production & $0.050<D_{95}<0.100$ & 0.3 & 0.008 & 38 & 0.727 \\
\hline WEEE plastic scraps & Maris et al. 2015 & 10 tons & $D_{95}>0.020$ & 5.5 & $*$ & 1,500 & 0.063 \\
\hline
\end{tabular}


repeating the sampling and the plastic identification, from another batch of 10 tons, repeatability was indeed good for ABS (29\% mass fraction), HIPS (26\%), PP (22\%). But repeatability was not good for less represented plastics (CVs $>0.5$ for PC-ABS 5\% mass fraction, PMMA 3\%, PC 3\%, PA $1 \%$ and 14 others $<1 \%$, total 21 polymers).

\subsubsection{Test portions}

Different cases are presented, from large to small test portions: laboratory percolation tests and leaching tests, aliquots for laboratory mineral digestion or organic extraction (Table 4). The maximum grain size and the mass of the test portions are given in the standards.

For test portions from laboratory sample, $\mathrm{n}$ is calculated with Equation 10, where the masses of the test portions are given in the standards, while the maximum grain size, as indicated in the standards, are multiplied by $\mathrm{g}$ (here set to 0.25 ) and a hypothetical solid density. For percolation and leaching tests, cases with the presence and non-presence of a fine fraction (i.e., $10 \%$ of particles characterized by a diameter $<1 \mathrm{~mm}$ ) were calculated.

For percolation and leaching tests, the number of particles calculated assuming absence of fines never reaches satisfactory values and is even around 300 in the leaching test with the $10 \mathrm{~mm}$ grain size (EN 12547-4, (2002)). This number of particles is also always lower than the number calculated with a hypothesis of $10 \%$ of particles $<1 \mathrm{~mm}$, which is a realistic assumption after the size reduction.

For analytical measurements (direct such as X-ray fluorimetry) or after digestion / extraction, the test portion calculated with Equation 10 is greater than or equal to 100,000 , except for the PBDE analysis. As the size reduction occurs, it is likely that the real number of particles in the test portions will be higher.

\section{CONCLUSIONS}

The theoretical principles behind the EU technical standards for granular waste sampling are reviewed to ease their application and understanding in the waste community. In particular, the formula given to calculate the mass of a laboratory sample (or test portion, equivalently), is reviewed in terms of number of particles that should be present in the sample to be representative of the batch of waste to be characterized. Practical aspects aimed at ensuring the "probabilistic" performance of sampling are not addressed (i.e., the qualitative instructions on "how to" sample).

Granular wastes are assumed as a population of particles characterized by a fraction showing a property of interest, which is the object of the measurement. Sampling is conceptually modelled as repeated drawings of particles, with the binomial probability distribution describing the probability of picking up a fraction of particles of interest "reliably" similar to that occurring in the waste lot. Single particle concentrations of $\mathrm{Br}$, determined in different samples of WEEE plastic scraps, are presented to discuss the distributions of properties of interest among particles in the waste field. When these are right-skewed by some rare

TABLE 4: Estimated number of particles ( $n$ ) in waste test portions as indicated in different analytical standards (Equation 10). The fraction of rare particles of interest $(p)$ which can be assessed with a theoretical $C V$ of 0.1 is calculated from Eq.7. $M_{\text {sam }}(\mathrm{kg})=$ mass of test portion as indicated in the specific reference. For $D_{95}$, psolid, $g$ and $f$ refer to Equation $10{ }^{a}=$ Calculated assuming a percolation column characterized by an internal diameter of $0.1 \mathrm{~m}$ and a bulk density and a solid density of the material of $1.6 \mathrm{~kg} \mathrm{~L}^{-1}$ and $2 \mathrm{~kg} \mathrm{~L}^{-1}$, respectively. ${ }^{\mathrm{b}}=$ calculated assuming a percolation column characterized by an internal diameter of $0.05 \mathrm{~m}$ and a bulk density and a solid density of the material of $1.6 \mathrm{~kg} \mathrm{~L}^{-1}$ and $2 \mathrm{~kg} \mathrm{~L}^{-1}$, respectively. ${ }^{\mathrm{c}}=$ calculated assuming a solid density of the material of $1.1 \mathrm{~kg} \mathrm{~L}^{-1} .{ }^{\mathrm{d}}=$ calculated assuming $^{\circ}$ a solid density of the material of $1.1 \mathrm{~kg} \mathrm{~L}^{-1}$.

\begin{tabular}{|c|c|c|c|c|c|c|}
\hline Standard & Reference & $\mathrm{D}_{95}(\mathrm{~m})$ & $\mathrm{M}_{\text {sam }}(\mathbf{k g})$ & $\frac{\pi}{6}\left(D_{95}\right)^{3} * \rho_{\text {solid }} * g * f$ & $n$ & $p(C V=0.1)$ \\
\hline \multirow[t]{4}{*}{ Percolation test } & \multirow[t]{4}{*}{ EN 14405} & 0.010, No fines & $3.8^{a}$ & 3.0E-04 & 14,400 & 0.007 \\
\hline & & $\begin{array}{c}0.010, \text { with } 10 \%< \\
1 \mathrm{~mm}\end{array}$ & $3.8^{a}$ & $5.2 \mathrm{E}-06$ & 730,769 & 0.0001 \\
\hline & & 0.004, No fines & $0.9^{b}$ & 1.7E-05 & 56,250 & 0.002 \\
\hline & & $\begin{array}{c}0.004 \text {, with } 10 \%< \\
1 \mathrm{~mm}\end{array}$ & $0.9^{b}$ & $4.6 \mathrm{E}-06$ & 195,652 & 0.001 \\
\hline \multirow[t]{5}{*}{ Leaching test } & \multirow[t]{2}{*}{ EN 12457-4 } & 0.010, No fines & $0.090^{c}$ & 3.0E-04 & 344 & 0.225 \\
\hline & & $0.010,10 \%<1 \mathrm{~mm}$ & $0.090^{c}$ & $5.2 \mathrm{E}-06$ & 17,308 & 0.006 \\
\hline & \multirow{2}{*}{$\begin{array}{l}\text { EN 12457-1 } \\
\text { EN 12457-2 }\end{array}$} & 0.004, No fines & $0.090^{c}$ & $2.0 \mathrm{E}-05$ & 5,371 & 0.018 \\
\hline & & $0.004,10 \%<1 \mathrm{~mm}$ & $0.090^{c}$ & $4.6 \mathrm{E}-06$ & 19,565 & 0.005 \\
\hline & EN $12457-3$ & 0.004 & $0.175^{c}$ & 2.0E-05 & 10,445 & 0.009 \\
\hline \multirow{2}{*}{$\begin{array}{l}\text { Elements XRF } \\
\text { analysis }\end{array}$} & \multirow[t]{2}{*}{ EN 15309} & 0.00015 & $0.010^{c}$ & $8.8 \mathrm{E}-10$ & $11,317,685$ & 0.000009 \\
\hline & & 0.00008 & $0.005^{c}$ & 1.3E-10 & $33,571,746$ & 0.000003 \\
\hline \multirow[t]{2}{*}{ Elements Digestion } & \multirow[t]{2}{*}{ EN 13656} & 0.00025 & $0.0002^{c}$ & 4.1E-09 & 48,892 & 0.002 \\
\hline & & 0.00025 & $0.0004^{c}$ & 4.1E-09 & 97,785 & 0.001 \\
\hline \multirow[t]{2}{*}{ PCB analysis } & \multirow[t]{2}{*}{ EN 15308} & 0.00050 & $0.010^{c}$ & 3.3E-08 & 305,577 & 0.0003 \\
\hline & & 0.00050 & $0.025^{c}$ & 3.3E-08 & 763,944 & 0.0001 \\
\hline PBDE products & EN 62321-6 & 0.00050 & $0.0001^{d}$ & $1.8 \mathrm{E}-08$ & 5,556 & 0.018 \\
\hline PBDE waste & EN 16377 & 0.00200 & $0.0030^{d}$ & $1.2 \mathrm{E}-06$ & 2,604 & 0.037 \\
\hline
\end{tabular}


particles (i.e., the fraction of particles of interest is much lower than the unity value), their occurrence (or non-occurrence) in the sample can remarkably influence the reliability of the measurement.

By knowing or estimating the fraction of particles "of interest" and by assuming a controlled degree of variability, this paper shows that samples from waste characterization campaigns must simply contain 100 particles of interest in order to be representative and not very variable. From this requirement, mass of representative samples or subsamples can be calculated according to the particles sizes distribution and their physical features. With these results, the recommended mass of laboratory samples and test portions as laid down in published sampling plans or analytical standards are assessed. Here, samples containing less particles could lead to a higher uncertainty/variability associated with the measurement of the parameter of interest.

Finally, real data on observed analytical variability (inter- and intra-laboratory) are discussed to check the reliability of the assumptions made to derive the number of particles in a representative sample or subsample.

In summary, the calculation of the size of the representative sample must be based on the knowledge of the waste consistency. The sampling of particles according to possibly occurring size-concentration relationship is addressed in a second paper of this series.

\section{ACKNOWLEDGEMENTS}

This study was carried out as part of the Ineris mission to support the Ministry of the Ecological Transition. Philippe Wavrer (CASPEO) and Frank Lamé (Deltares) are warmly thanked for sharing their experience in the field of waste sampling.

\section{REFERENCES}

Bunge R, Bunge K. 1999. Probenahme auf Altlasten: Minimal notwendige Probenmasse. Altlasten Spektrum 3/99: 174-179. (Sampling on contaminated sites: Minimal necessary sample mass).

Bunge R. 2019. Recovery of metals from waste incinerator bottom ash. 85 p. Metals_from_MWIBA.pdf from www.umtec.ch or www. igenass.ch

CLC/TS 50625-3-2, 2016. Collection, logistics \& Treatment requirements for WEEE - Part 3-2: Technical specification for de-pollution - Lamps. CEN, Brussels, Belgium.

CEN/TR 15310-1, 2007. Characterization of waste - Sampling of waste materials Part 1: Guidance on selection and application of criteria for sampling under various conditions. CEN, Brussels, Belgium.

CENELEC CLC/TS 50625-3-1, 2015. Requirements for the collection, logistics and treatment of WEEE - Part 3-1: Specification relating to depollution - General. CENELEC, Brussels, Belgium.

Chimenos J M, Segarra M, Fernandez M A, Espiell F. 1999. Characterization of the bottom ash in municipal solid waste incinerator. Journal of Hazardous Materials A:64 (1999) 211-222.

Eco-Mobilier, Valdelia 2018. Programme de recherche et développement visant à caractériser finement les déchets de bois issus des filières REP Eco-mobilier et Valdelia dans l'objectif d'une valorisation en chaudière biomasse. Rapport de phase 1. Etude CEDEN. 22/11/2018. 94 p.

EN 12457-1, 2002. Characterization of waste - Leaching - Compliance test for leaching of granular waste materials and sludges Part 1: One stage batch test at a liquid to solid ratio of $2 \mathrm{l} / \mathrm{kg}$ for materials with high solid content and with particle size below 4 $\mathrm{mm}$ (without or with size reduction). CEN, Brussels, Belgium.
EN 12457-2, 2002. Characterization of waste - Leaching - Compliance test for leaching of granular waste materials and sludges Part 2: One stage batch test at a liquid to solid ratio of $10 \mathrm{l} / \mathrm{kg}$ for materials with particle size below $4 \mathrm{~mm}$ (without or with size reduction). CEN, Brussels, Belgium.

EN 12457-3, 2002. Characterization of waste - Leaching - Compliance test for leaching of granular waste materials and sludges Part 3: Two stage batch test at a liquid to solid ratio of $2 \mathrm{l} / \mathrm{kg}$ and 8 $\mathrm{l} / \mathrm{kg}$ for materials with high solid content and with particle size below $4 \mathrm{~mm}$ (without or with size reduction). CEN, Brussels, Belgium.

EN 12457-4, 2002. Characterization of waste - Leaching - Compliance test for leaching of granular waste materials and sludges - Part 4: One stage batch test at a liquid to solid ratio of $10 \mathrm{l} / \mathrm{kg}$ for materials with particle size below $10 \mathrm{~mm}$ (without or with size reduction). CEN, Brussels, Belgium.

EN 13656, 2020. Soil, treated biowaste, sludge and waste - Digestion with a hydrochloric $(\mathrm{HCl})$, nitric $(\mathrm{HNO})$ and tetrafluoroboric (HBF4) or hydrofluoric (HF) acid mixture for subsequent determination of elements. CEN, Brussels, Belgium.

EN 14405, 2017. Characterization of waste - Leaching behaviour test - Up-flow percolation test (under specified conditions). CEN, Brussels, Belgium.

EN 14899, 2006. Characterization of waste - Sampling of waste materials - Framework for the preparation and application of a Sampling Plan. CEN, Brussels, Belgium.

EN 15002, 2015. Characterization of waste - Preparation of test portions from the laboratory sample. CEN, Brussels, Belgium.

EN 15308, 2017. Characterization of waste - Determination of selected polychlorinated biphenyls (PCB) in solid waste by using capillary gas chromatography with electron capture or mass spectrometric detection

EN 15309, 2007. Characterization of waste and soil - Determination of elemental composition by X-ray fluorescence. CEN, Brussels, Belgium.

EN 15413, 2011. Solid recovered fuels - Methods for the preparation of the test sample from the laboratory sample. CEN, Brussels, Belgium.

EN 16181, 2018. Soil, treated biowaste and sludge - Determination of polycyclic aromatic hydrocarbons (PAH) by gas chromatography (GC) and high performance liquid chromatography (HPLC).

EN 16167, 2018. Soil, treated biowaste and sludge. Determination of polychlorinated biphenyls (PCB) by gas chromatography with mass selective detection (GC-MS) and gas chromatography with electron-capture detection (GCECD).

EN 16190, 2018. Soil, treated biowaste and sludge - Determination of dioxins and furans and dioxin-like polychlorinated biphenyls by gas chromatography with high resolution mass selective detection (HR GC-MS).

EN ISO $11348-3,2008$. Water quality - Determination of the inhibitory effect of water samples on the light emission of Vibrio fischeri (Luminescent bacteria test) - Part 3: Method using freeze-dried bacteri. CEN, Brussels, Belgium.

EN ISO 8692, 2012. Water quality - Fresh water algal growth inhibition test with unicellular green algae. CEN, Brussels, Belgium.

ISO 18187, 2018. Contact test for solid samples using the dehydrogenase activity of Arthrobacter globiformis. CEN, Brussels, Belgium.

ISO 17512-1, 2020. Soil quality. Avoidance test for determining the quality of soils and effects of chemicals on behaviour. Test with earthworms (Eisenia fetida and Eisenia andrei). CEN, Brussels, Belgium.

EN 62321-6, 2015. Determination of certain substances in electrotechnical products. Polybrominated biphenyls and polybrominated diphenyl ethers in polymers by gas chromatography-mass spectrometry (GC-MS). CEN, Brussels, Belgium.

EN 16377, 2013. Characterization of waste - Determination of brominated flame retardants (BFR) in solid waste. CEN, Brussels, Belgium.

Eurachem, CITAC, 2012. Quantifying Uncertainty in Analytical Measurements.

Eurachem, CITAC, 2019. Measurement uncertainty arising from sampling.

Gy P. 2004a. Sampling of discrete materials-a new introduction to the theory of sampling: I. Qualitative approach. Chemometrics and Intelligent Laboratory Systems, Volume 74, Issue 1, 28 November 2004, 7-24. 
Gy P. 2004b. Sampling of discrete materials: II. Quantitative approachsampling of zero-dimensional objects. Chemometrics and Intelligent Laboratory Systems, Volume 74, Issue 1, 28 November 2004, 25-38

Gy P. 2004c. Sampling of discrete materials: III. Quantitative approach-sampling of one-dimensional objects. Chemometrics and Intelligent Laboratory Systems, Volume 74, Issue 1, 28 November 2004, 39-47.

Gy P. 2004d. Part IV: 50 years of sampling theory-a personal history. Chemometrics and Intelligent Laboratory Systems, Volume 74, Issue 1, 28 November 2004, 49-60.

Haarman, A., Gasser, M., Böni, H., Rösslein, M. \& Wäger, P. Brominated Flame Retardants in Large Household Appliances. (2018). URL: https://www.bsef.com/wp-content/uploads/2020/11/Study-onthe-impact-of-Brominated-Flame-Retardants-BFRs-on-WEEE-plastics-recycling-by-Sofies-Nov-2020.pdf

Hennebert P, Filella M. 2018. WEEE plastic sorting for bromine essential to enforce EU regulation. Waste Management, 71, January 2018, 390-399.

Hennebert, P., 2018. Proposal of concentration limits for determining the hazard property HP 14 for waste using ecotoxicological tests. Waste Manag. 74, 74-85. https://doi.org/10.1016/j.wasman.2017.11.048

Hennebert P. 2020. Concentrations of brominated flame retardants in plastics of electrical and electronic equipment, vehicles, construction, textiles and non-food packaging: a review of occurrence and management. Detritus. DOI 10.31025/2611-4135/2020.13997

Holm O, Simon F-G. 2017. Innovative treatment trains of bottom ash (BA) from municipal solid waste incineration (MSWI) in Germany. Waste Management, Volume 59, January 2017, Pages 229-236

Kalbe, U., Lehnik-Habrink, P., Bandow, N. et al. Validation of European horizontal methods for the analysis of PAH, PCB and dioxins in sludge, treated biowaste and soil. Environ Sci Eur 31, 29 (2019). https://doi.org/10.1186/s12302-019-0211-3

Khodier K, Viczek S. A, Curtis A, Aldrian A, O'Leary P, Lehner M, Sarc R. 2019. Sampling and analysis of coarsely shredded mixed commercial waste. Part I: procedure, particle size and sorting analysis. International Journal of Environmental Science and Technology (2020) 17:959-972 https://doi.org/10.1007/s13762-019-02526-w
LAGA PN 98: Richtlinie für das Vorgehen bei physikalischen, chemischen und biologischen Untersuchungen im Zusammenhang mit der Verwertung/Beseitigung von Abfällen; Länderarbeitsgemeinschaft Abfall. Kiel, 2001. (LAGA PN 98: Guideline for the handling of physical, chemical and biological investigations in connection with the recovery / disposal of waste; Country Working Group on Waste. Kiel, 2001.)

Maris E, Botané P, Wavrer P, Froelich D. 2015. Characterizing plastics originating from WEEE: A case study in France. Minerals Engineering 76 (2015) 28-37.

Pandard, P., Römbke, J., 2013. Proposal for a "Harmonized" Strategy for the Assessment of the HP 14 Property. Integr. Environ. Assess. Manage. 9 (4), 665-672.

SVDU 1995. Syndicat national du traitement et de la valorisation des déchets urbains et assimilés. Guide méthodologique pour l'échantillonnage des mâchefers d'usine d'incinération d'ordures ménagères. $42 \mathrm{p}$. https://www.fedene.fr/wp-content/uploads/ sites/2/2017/09/FG3E-FR_MIOM_Echantillonnage_0.pdf

van der Sloot, H.A., O. Hjelmar, J. Bjerre Hansen, P. Woitke, P. Lepom R. Leschber, B. Bartet, N. Debrucker. 2001. Validation of CEN/TC 292 Leaching Tests and Eluate Analysis Methods PrEN 12457 part 1- 4, ENV 13370 and ENV 12506 in Co-operation with CEN/TC 308. 2001. Report ECN-C-01-117.

Vencovsky D, Garrett S, Vencovska J, Shapland I, La Vedrine M, Ciatt F, White S, Webb S, Postle M, Hennebert P, Bisson M, Biaudet H, Lestremeau F, Cavalieri L, Mudgal S. 2021. Study to support the assessment of impacts associated with the review of limit values in waste for POPs listed in annexes IV and V of Regulation (EU) 2019/1021. Report for the Directorate General Environment of the European Union. Final Report. 427 p.

Wäger P, Schluep M, Müller E, Gloor R. 2011. RoHS regulated substances in mixed plastics from Waste Electrical and Electronic Equipment. Environ. Sci. Technol. 2012, 46, 628-635 